\title{
Diagnostics of brewing
}

\author{
Beer is a high-quality product that comes with a dedicated set of units. Stefanie Reichert and Bart Verberck \\ elaborate on the most common ones.
}

T he history of beer reaches far back into humankind's past: the first evidence of beer brewing dates to the fifth millennium вс. Ordinances regulating beer brewing and distribution were already issued by the Babylonian king Hammurabi, threatening death by drowning in one's own beer barrels or suffocating from an oversupply of beer for anyone producing or selling adulterated product. Today, punishments for violations of current beer legislations (such as the famous German Reinheitsgebot allowing only water, hops, yeast and barley as ingredients) are of course less draconian.

Although regulations have been loosened, the brewing process adheres to strict rules. In Germany, the type of yeast, the alcohol by volume and the so-called Stammwürzegehalt or simply Stammwürze - a measure for the amount of extract in the wort after adding yeast - are used to classify the beer. Stammwürze characterizes the 'strength' of a beer; its unit is degree Plato $\left({ }^{\circ} \mathrm{P}\right)$, after the German chemist Fritz Plato. At a temperature of $20^{\circ} \mathrm{C}, 1^{\circ} \mathrm{P}$ corresponds to $1 \mathrm{~g}$ of extract in $100 \mathrm{~g}$ of wort. Light beers have a Stammwürze of up to $7^{\circ} \mathrm{P}$; strong beers have $16^{\circ} \mathrm{P}$ or more ${ }^{1}$. At the Oktoberfest festival in Munich, beer served must have at least $13.5^{\circ} \mathrm{P}$ (ref. ${ }^{2}$ ).

A beer-strength unit commonly used in other countries is the specific gravity: the ratio between the extract density and the density of a reference substance such as pure water. Often, original and final gravity are given, referring to the density before and after fermentation, respectively. For the conversion between specific gravity and ${ }^{\circ} \mathrm{P}$, formulas exist, but as an approximate rule of thumb, one can calculate $259 \times\left(1-1 / g_{s}\right)$ to obtain the Stammwürze in ${ }^{\circ} \mathrm{P}$ (ref. ${ }^{3}$ ). A Belgian Tripel, for example, has original gravity $g_{\mathrm{s}}$ around 1.080 , corresponding to about $20^{\circ} \mathrm{P}$ (ref. ${ }^{4}$ ).

Apart from alcoholic content and density, there are other, optical beer parameters: colour and turbidity ('cloudiness'). Whether a beer is hazy or transparent is obvious when the beer is poured (pictured), but to determine the exact ingredients that make it turbid or

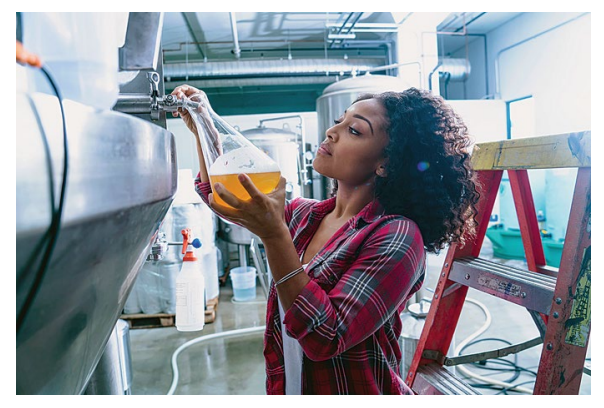

Credit: Cultura Creative (RF) / Alamy Stock Photo

even invisibly hazy requires a more complex approach: nephelometry. Light of a specific wavelength is directed onto a beer sample, and the scattering angle with respect to the incoming light's axis provides information on whether smaller particles (proteins or carbohydrates) or larger ones (such as yeast, among others) are causing the beer's haze. The turbidity is then often calibrated with respect to the well-known synthetic material formazin and given in various units such as the nephelometric turbidity unit or the formazin nephelometric unit.

Properly measuring a beer's colour was pioneered by British brewer James William Lovibond in the 1880s. His method consisted of comparing the colour of a sample to a set of standardized glass slides, with colours ranging from amber to dark brown - either visually (originally) or with a colorimeter (as happens nowadays). As this method was not very accurate, the measure was replaced by the Standard Reference Method (SRM) colour system and, as an alternative, by a colour unit introduced by the European Brewery Convention (EBC). The SRM and EBC units both have a spectrophotometric origin; the attenuation of light at $430 \mathrm{~nm}$ (blue-violet) is measured as it passes through $1 \mathrm{~cm}$ of beer contained in a standard $1 \mathrm{~cm}$ by $1 \mathrm{~cm}$ cuvette. The SRM unit ranges from around 2 for pale lagers, over 20 for brown ales and around 40 for stouts ${ }^{5}$. The conversion from SMR to EBC units is approximately equivalent to multiplying by a factor of 2 .
The taste of the beer itself is measured in terms of bitterness. Not the perceived bitterness, but the taste experience stemming from alpha acids - organic molecules present in the flowers of the hop plant. Common scales are the International Bittering Unit (IBU) and the European Bitterness Unit (EBU), which are almost equal. A hoppy India pale ale is found at the top of the scale (40-120 IBUs), whereas lambics are the least bitter (0-10 IBUs) ${ }^{6}$. Typically, the amount of alpha acids is determined by spectrophotometry of a sample of hops boiled in wort; mass and fluorescence spectroscopy or highperformance liquid chromatography are used as alternative techniques.

Home brewers need to find a way around using complicated and expensive techniques to determine the properties of their beer. For example, the density of the wort can be easily determined with a refractometer (often calibrated at a reference temperature), but it's not trivial to determine the density of the final product as alcohol and the dissolved sugar have different refraction indices. One can correct for this effect with a formula, provided the refraction indices are known before and after fermentation.

In the end, after all measurements related to the brewing process itself are completed, there's one last check to be made - sampling the beer to ensure all efforts were worth it. But, needless to say, always drink responsibly.

\section{Stefanie Reichert ${ }^{1}$ and Bart Verberck ${ }^{2}$ \\ ${ }^{1}$ Associate editor at Nature Physics. ${ }^{2}$ Regional executive editor for Nature Research. e-mail: stefanie.reichert@nature.com; bart.verberck@nature.com}

Published online: 1 February 2019

https://doi.org/10.1038/s41567-019-0419-6

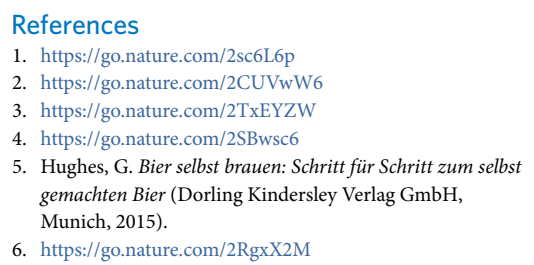

\begin{tabular}{|c|c|c|c|c|c|c|c|c|c|c|c|c|c|c|c|c|}
\hline $\mathrm{m}$ & $e$ & $\AA$ & $\mathrm{S}$ & $\mathrm{u}$ & $R$ & $E_{\mathrm{h}}$ & $F$ & $\Omega$ & ${ }^{\circ} \mathrm{R}$ & $\mu_{0}$ & $\varepsilon_{0}$ & $\alpha$ & $\sigma$ & $\mathrm{V}$ & $\mathrm{R}$ & e \\
\hline
\end{tabular}

